\title{
The Dirt of Development: Nature's Role in Social-Emotional Development and Parent-Child Connectedness
}

\author{
Hayley Johanna Lindsey \\ West Virginia University, hjlindsey@mix.wvu.edu
}

Follow this and additional works at: https://researchrepository.wvu.edu/etd

Part of the Early Childhood Education Commons

\section{Recommended Citation}

Lindsey, Hayley Johanna, "The Dirt of Development: Nature's Role in Social-Emotional Development and Parent-Child Connectedness" (2019). Graduate Theses, Dissertations, and Problem Reports. 3760. https://researchrepository.wvu.edu/etd/3760

This Thesis is protected by copyright and/or related rights. It has been brought to you by the The Research Repository @ WVU with permission from the rights-holder(s). You are free to use this Thesis in any way that is permitted by the copyright and related rights legislation that applies to your use. For other uses you must obtain permission from the rights-holder(s) directly, unless additional rights are indicated by a Creative Commons license in the record and/ or on the work itself. This Thesis has been accepted for inclusion in WVU Graduate Theses, Dissertations, and Problem Reports collection by an authorized administrator of The Research Repository @ WVU. For more information, please contact researchrepository@mail.wvu.edu. 
The Dirt of Development:

Nature's Role in Social-Emotional Development and Parent-Child Connectedness

\author{
Hayley J. Lindsey
}

Thesis submitted

to the College of Education and Human Services

at West Virginia University

in partial fulfillment of the requirements for the degree of

Master of Arts in

Educational Psychology with an emphasis in Child Development and Family Studies

Amy Root, Ph.D., Committee Chair

Jessica Troilo, Ph.D.

Abhik Roy, Ph.D.

Department of Learning Sciences and Human Development

Morgantown, West Virginia

2019

Keywords: child development, nature, parent-child, social-emotional, prosocial behavior Copyright 2019 Hayley J. Lindsey 


\begin{abstract}
The Dirt of Development:

Nature's Role in Social-Emotional Development and Parent-Child Connectedness
\end{abstract}

Hayley J. Lindsey

The purpose of this study was to examine associations between nature connectedness, parentchild connectedness, and the development of prosocial behavior. Nature connectedness pertains to the strong emotional affinity towards the natural environment and is linked with happiness, stress reduction, and good health. Prosocial behavior refers to actions or behaviors done with the intent to help others. This study consisted of 467 parent-informants that gathered information on the parent's nature connectedness, the child's nature connectedness, the parent-child connectedness, and the child prosocial behavior. Gaps in the literature were addressed by analyzing the role that parent nature connectedness has in predicting child nature connectedness, two variables that prior studies have yet to do. The findings of this study also suggest parent and child nature connectedness as being supportive of the parent-child relationship. The findings of this study have practical, applied implications for parents, educators, and practitioners due to the positive developmental outcomes and associations of nature connectedness and parent-child connectedness. 


\section{Dedication}

To my parents,

For igniting the spark that has fueled my passion for the great outdoors and for traveling.

For propagating tenacity by planting seeds of opportunity sown through to fruition.

For instilling in me your sense of ambition that has gotten me where I am today.

For teaching me to not only face, but embrace, life's thunderstorms.

For being the most resourceful guidebook a child could have.

For being the wayfinding compass as well as the moral.

For letting us get a little dirty digging for worms.

For cultivating a healthy and happy home.

Although perennials must leave from time to time, they remain deeply rooted in the groundwork that grew them, merely waiting for the harsh winter to subside so that they may make their way back home. 


\section{Acknowledgements}

To my exceptional committee - I truly appreciate all of your continued assistance throughout this grand adventure.

Special thanks go to my committee chair, Dr. Amy Root for her above-and-beyond dedication not only to her advisee and this project, but also to the college overall. Your hard work does not go unnoticed. 


\section{Table of Contents}

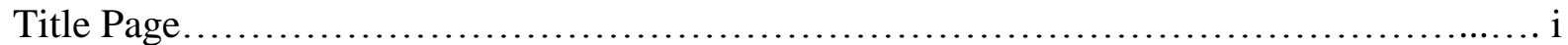

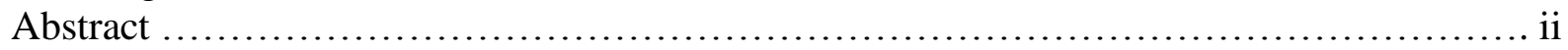

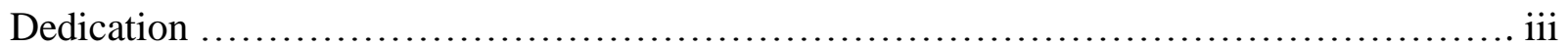

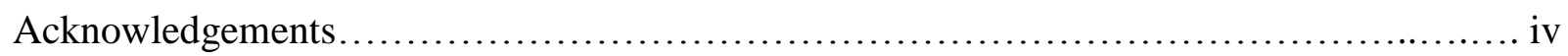

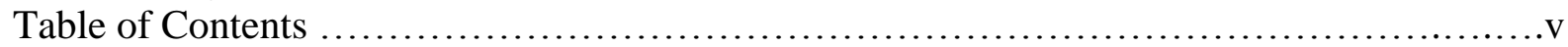

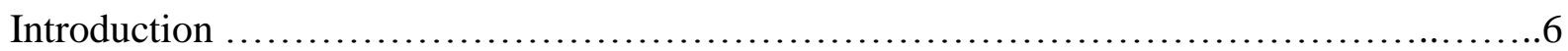

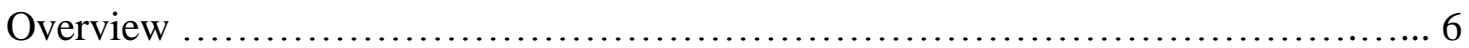

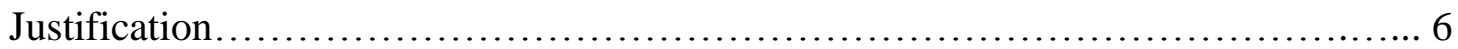

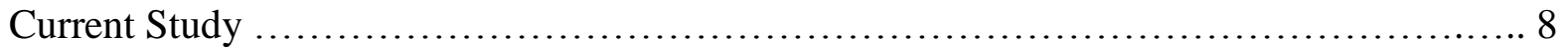

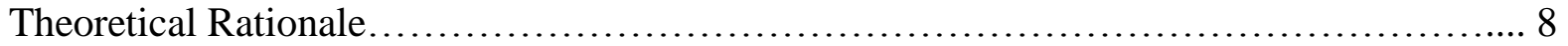

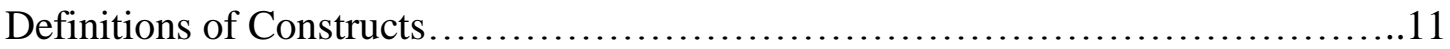

Nature Contact ........................................................ 11

Nature Connectedness ...............................................12

Nature Connectedness: Socialization and Associated Outcomes....................13

Parent-Child Connectedness...........................................13

Parent-Socialization of Children to Nature...................................14

Nature Connectedness and Developmental Outcomes......................15

Prosocial Behavior................................................... 15

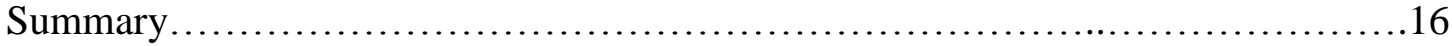

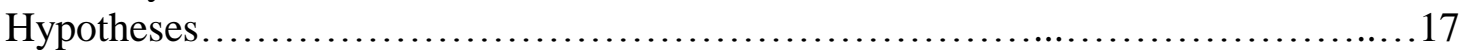

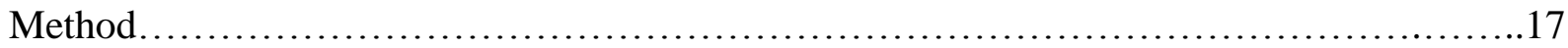

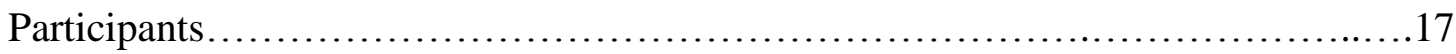

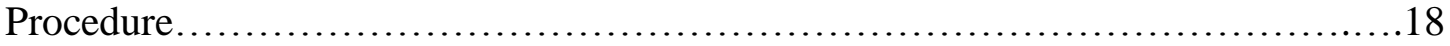

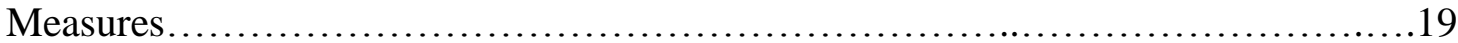

Parent Nature Connectedness...........................................19

Child Nature Connectedness............................................19

Parent-Child Connectedness...............................................20

Child Prosocial Behavior................................................20

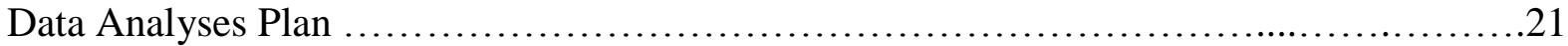

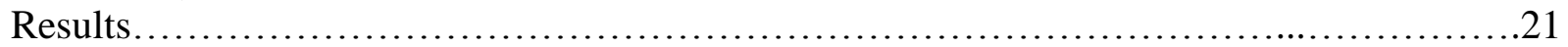

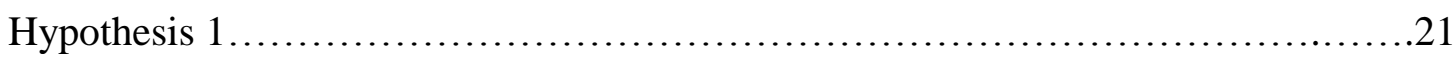

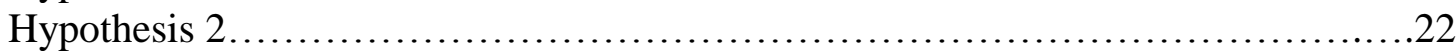

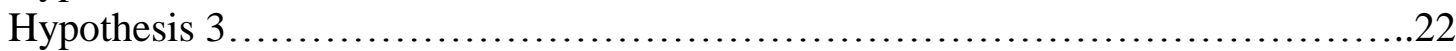

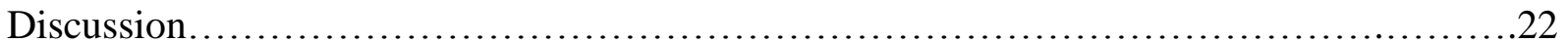

Strengths, Limitations, and Future Directions.................................26

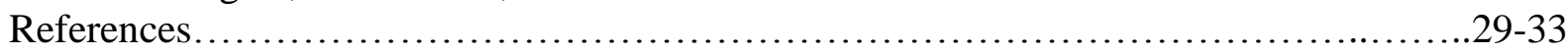

Tables

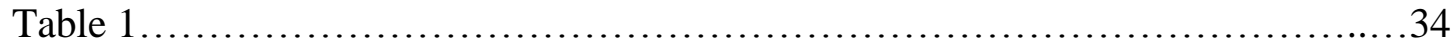

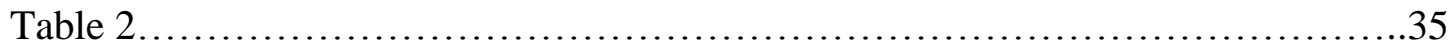

Appendices

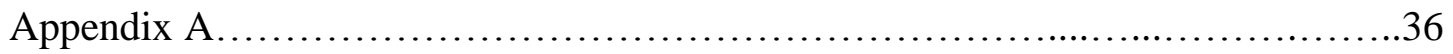

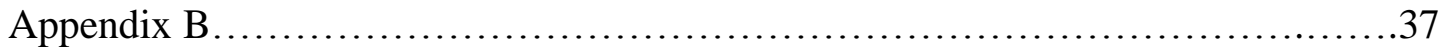

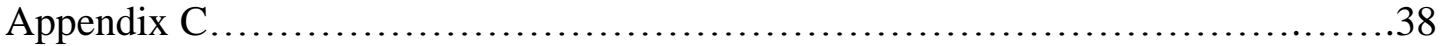

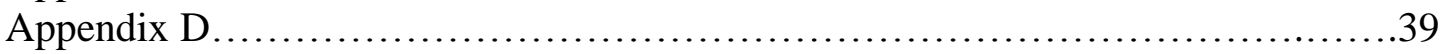


Introduction

\section{Overview}

It has long been understood that contact with nature has beneficial components for overall well-being (Wilson, 1984) as well as for relationship interactions (Keisanen, Rauniomaa, \& Siitonen, 2017); however, research has yet to encompass just how grand of a role the great outdoors has in developing children and family life. Contact with nature is suggestive of nature connectedness, which is viewed as the strong affinity towards and emotional connection with nature that many experience (Wilson, 1984). This partiality towards nature is supportive of physical health, including the reduction of stress improved well-being (Mayer \& McPherson, 2004). It also provides a benefit environment for the socialization of positive interpersonal interactions and the development of socio-emotional skills (Barros, Silver, \& Stein, 2009; Ibrahim \& Torquati, 2015). This is important due to the large role that parents already play in socializing their children to the world around them (Bornstein, 2015). The limited available literature suggests that parental socialization of children to the outdoors is an important contributor to children's developmental outcomes; yet, research remains sparse, especially in how nature supports the development of prosocial behavior and family relationships.

\section{Justification}

Even though connection with nature promotes positive developmental outcomes, such as overall well-being and happiness, children are spending less time outdoors (Bento \& Dias, 2017). They are growing up without easily accessible natural areas for exploration and play and, as a result, are not developing a secure connection to nature nor the positive health affordances that accompany such contact (Seymour, 2016). Collectively, a lack of nature appreciation from a society can have devastating consequences on nature conservation efforts and initiatives, as 
children who are not socialized to appreciate nature and see the value in it might not want to make efforts to preserve it or continue to use it (Strife \& Downey, 2009). Increasing levels of urbanization in modern society have been shown to be one of the main factors in children's decreased use of natural areas over time (Bento \& Dias, 2017); however, parental choices may be to blame as well, as parents are often a primary socialization agent in their offspring's life (Bornstein, 2015; Keisanen et al., 2017). This widely apparent decline in connection with nature is an issue of research that is of interest for developmental psychologists, parents, policymakers, and healthcare officials alike due to its impact worldwide and because of its link with children's' developmental outcomes and overall well-being (Frumkin et al., 2017).

Although research has been conducted on the association between nature contact and perceived nature connectedness (Frumkin et al., 2017), many gaps remain in regard to how nature contact is socialized, as well as how it impacts parent-child connectedness and the development of socio-emotional behaviors. Particularly, a gap exists in the role that parents' nature connectedness has on parent-child connectedness. Moreover, while contact with nature has been widely shown to be a process that promotes overall well being and positive developmental outcomes research has yet to determine the association of parents' historical contact with nature and their offspring's level of nature connectedness (Frumkin et al., 2017). More thorough examination is needed in regards to the role that parents' childhood experiences in nature impact their future children's connection to nature, as well as the family's nature connectedness throughout the lifespan. While this body of work exists, further research is needed to address gaps in literature regarding parents' role of socializing children to nature connectedness.

Biophilia Hypothesis. The biophilia hypothesis has been used in the past to strengthen 
the case for equitable access for all to nature (Wilson, 1984). The biophilia hypothesis is a relatively established concept in the natural sciences (Bratman, Hamilton, Daily, 2012; Keniger, Gaston, Irvine, \& Fuller, 2013; Lumber, Richardson, \& Sheffield, 2017; Mayer, Frantz, Bruehlman-Senecal, \& Dolliver, 2009). Seymour (2016) describes the biophilic nature of humans (biophilia) as a tendency towards the natural world, and that this tendency is an innate need and enduring esthetic preference for the natural environments. Other evidence has suggested that biophilia is universally felt by all and genetically rooted in humans' evolutionary history (Bratman, Hamilton, \& Daily, 2012). Thus, it seems important to better understand how nature connectedness develops, given its association with human health and development (Beyer et al., 2015).

\section{Current Study}

Three primary research questions directed the current study: (1) Is there a correlation between nature connectedness and the relationship that one has with his or her parent/child?; (2) Is time spent in nature during childhood predictive of later extent to which one exposes his or her own child to nature?; and (3) Is there an association between time spent outdoors and socioemotional learning - specifically that of prosocial behavior? Thus, the current study was subsequently designed to examine the relations between parents' nature connectedness and parent-child connectedness; parent's nature connectedness and child's nature connectedness; and child's nature connectedness and the development of prosocial behaviors.

\section{Theoretical Rationale}

One way to conceptualize the importance of studying not only parents' role in children's development, but also nature's role is by using Super and Harkness' (1986) developmental niche theoretical framework. The developmental niche is a child-centered theory that analyzes the 
environmental and cultural influences on the child's development using three main criteria: (1) the settings of daily life (physical and social), (2) the cultural customs of childcare and child rearing, and (3) caretaker psychology (Super \& Harkness, 1986). Each of these components are said to be distinct from one another yet operating in conjunction with each other in order to form the complete cultural context.

The developmental niche is of relevance to the current study in several ways. First, a primary focus of the study is the role that nature has on the development of children. With one of the three components of the developmental niche being the physical setting in which the child lives (Super \& Harkness, 1986), it is appropriate to apply nature's existence (or non-existence) in the physical settings of daily life within the study. Parents reinforce nature connectedness by providing their children with the environment for nature contact to occur, thereby further increasing the likelihood that the child will develop nature connectedness themselves. Parents also reinforce it by showing their own nature connectedness through their enjoyment of the outdoors. Super and Harkness (1986) say that parents socialize their children by using language and demonstrated behaviors to teach their children obedience and responsibility (likely without even realizing it) and that the psychology of the caretakers (otherwise mentioned as parenting beliefs) facilitates socialization in general due to the importance placed by parents on language and social development in determining child intelligence. In their study, Super and Harkness (1986) found that when the child demonstrated helping abilities without being reminded to do so, and/or they exhibited emotion regulation abilities, the parent was more likely to view them as mature, responsible, obedient, and intelligent. In turn, these were used to determine the developmental appropriateness of the setting in which the child was exposed to. These culturally constructed theories of obedience and responsibility influenced the internalized parenting 
beliefs/caretaker psychology. For example, a parent noticing a child's demonstrated maturity would determine whether or not the child was old enough to run errands on his own (Super \& Harkness, 1986).

Secondly, the developmental niche has a large cultural component (Super \& Harkness, 1986).This can be related to the cultural customs that parents have been socialized to throughout their whole lives, later contributing to their internalized working models of childcare and childrearing. If a culture at large accepts or denounces outdoor engagement, parents are likely to follow suite. It was more customary several decade ago for children to be left unsupervised for several hours while playing outside - something that is often not accepted present-day, especially for younger children. Even though parents might feel it okay, the current custom of the culture is a stricter parental monitoring technique, allowing for less child autonomy in the outdoors.

And lastly, parents' own caretaker psychology is useful to incorporate into the interpretation of this study's findings because parents socialize their children to nature through their own demonstrated level of nature connectedness, showing how a child should or should not be connected to nature. As Bornstein (2015) and Bowlby (1969) suggest, parents play an important role in the development of children. In relation to the developmental niche, they are at least initially the primary controllers of where a child is, so they regulate the child's social setting that they are exposed to. More precisely, parents determine the extent to which the child engages in nature contact, which is important to this study because it is known that higher levels of nature contact contribute to a better sense of nature connectedness (Mayer et al., 2009).

The current study's overall link to the developmental niche is through children's social and physical setting, which are largely determined by the parents' caretaker psychology. This determines the extent that a parent feels it is necessary to socialize their children to nature. One 
way that this might look is by parents who value nature connectedness likely engage in parenting behaviors that reinforce this notion; they are also likely to see nature as something that improves children's development and, in turn, likely to make the effort to get their kids outside. Parents with higher levels of nature connectedness likely incorporate higher levels of nature contact into their internalized caretaker psychology, as they can see value in it and thus view it as important

for their child's development. Moreover, the developmental niche helps with the interpretation of the study's findings because of the examination of the connection between setting, culture, and caregiver beliefs (Super \& Harkness, 1986).

\section{Definitions of Constructs}

The wide array of definitions for central concepts that researchers in this field use requires clearly defined explanations of terms used in this study. Without defining these terms, misunderstandings of the central concepts of nature contact and nature connectedness can lead to confusion and interfere with the practical application and interpretation of research. Thus, a clearly defined set of definitions follows.

Nature Contact. Due to the varying interpretations and descriptions of the term nature contact, it is necessary to define exactly how it should henceforward be considered in this paper. The initial component of the expression, nature, can be understood as areas that are occupied by living systems in which plants and animals reside, coexisting across multiple planes and degrees of human interference and management throughout time (Bratman et al., 2012). The latter part of the term, contact, refers to the differing forms of interaction with, exposure to, and association with the former part of the term, nature (Frumkin et al., 2017). Thus, the combined term, nature contact, is to be understood throughout the context of this paper as the extent to which interaction occurs with different forms of natural elements within living systems over time. 
Nature contact occurs directly and indirectly. Activities as simple as walking to the mailbox to check the mail, playing outside during recess, or reading storybooks that happen to take place outdoors all provide the opportunity for nature contact to occur. Each instance in which a child is exposed to nature impacts how the child perceives and begins to make sense of the natural world around them, forming their internal working model (their understanding) of what is or is not important in life. This, then, presents the opportunity for nature connectedness to begin to form (to be described below).

Nature Connectedness. An equally important term to understand within the context of this paper is that of nature connectedness. The initial word, nature, can again be defined as areas that are occupied by living systems in which plants and animals reside, coexisting across multiple planes and degrees of human interference and management throughout time (Bratman et al., 2012). Unlike the phrase in the former paragraph, however, the latter term, connectedness, is indicative of some sort of intimateness or closeness with something (Laaksoharju \& Rappe, 2017). Keniger et al. (2013) describe nature connectedness as an instinctive connection to and love for the outdoors and other natural settings. Combined, the expression nature connectedness should be thought of throughout this paper as closeness with the natural world - an emotional affinity towards nature; whereas nature contact is simply the extent of exposure to natural elements.

Nature connectedness has been measured using the Nature Relatedness Scale (Lumber, Richardson \& Sheffield, 2017), the Inclusion of Nature in Self Scale (Schultz, 2002), the Connectedness to Nature Scale (Mayer \& Frantz, 2004), and the Parents of Preschool ChildrenConnectedness to Nature Index (Sobko, Jia, \& Brown, 2018). The Connectedness to Nature Scale (Appendix A) was used in this study to determine parent nature connectedness (Mayer \& 
Frantz, 2004). The Parents of Preschool Children-Connectedness to Nature Index (Appendix B) was used in this study to determine child nature connectedness (Sobko, Jia, \& Brown, 2018). Both are self-report measures. The connectedness to nature scale (CNS) is a fourteen-item measure that has been used to assess overall wellbeing, nature connectedness levels, and environmentally responsible behaviors using indicators of high, medium, low, and nonexistent. The inclusion of nature in self scale (INS) is a single-item measure that tests for closeness (affinity) towards nature - otherwise known as nature connectedness.

\section{Nature Connectedness: Socialization and Associated Outcomes}

Parent-child connectedness. Parent-child connectedness is to the degree of emotional closeness, warmth, and support that is experienced within a parent-child relationship (Braithwaite, Steele, Spjut, Dowdle, \& Harper, 2015). It is important to study of child socialemotional development overall because more positive, supportive, engaged relationships have been shown to increase the child's developmental outcomes (Bornstein, 2015; Clark \& Ladd, 2000), with highly connected parent-child relationships being distinctively related to successful socialization outcomes in children (Grusec \& Davidov. 2015). Because positive parent-child interactions increase attachment security of the relationship over time (McFarland, Zajicek, \& Waliczek, 2014) and because nature contact is associated with a decline in stress levels and elevated moods (Ulrich, Simons, Losito, Fiorito, Miles, \& Zelson, 1991), it is likely that nature can help facilitate positive human interaction, which, in turn, could increase the likelihood of a secure parent-child attachment and level of connectedness through the shared enjoyment of the activity (Bratman et al., 2012). One study even found that children were more likely to feel a stronger emotional connection to both of their parents after having participated in an outdoor, nature-based treatment program (Bettmann \& Tucker, 2011). Thus, it seems that parents who 
socialize nature connectedness and nature contact might also foster stronger relations with their children.

Parent socialization of children to nature. Because parents are one of the most important socialization agents of children throughout their lifetime, they play a large part in their children's socialization to nature contact (Grusec \& Davidov, 2015; Strife \& Downey, 2009). They show their child the ways of a society through their direct and indirect modeled behavior (Laible, Thompson, \& Froimson, 2015). Indirect exposure to nature is recognized by Frumkin et al. (2017) as events in time that occur in or around nature but the purpose of them is not solely derived from the need for nature contact; such as simply walking outside from the house to the driveway to get into the car. These indirect exposures to nature are important in the development of nature connectedness, especially for those that do not have parents that elect to frequently socialize their children directly to nature, as they will already have less nature contact than those who do. Furthermore, the context that one is situated in is another large determining factor in the proximity that a child has to nature, thus, parents' decision on where to live can be a limiting factor in the child's potential for contact with nature from the beginning.

Parents more directly socialize their children to nature through their control of how and when the children are (or are not) exposed to nature. Direct exposure to nature is the meaningful, intentional contact with nature or natural scenery, such as purposefully choosing to exercise or play outdoors as opposed to remaining indoors (Frumkin et al., 2017). Parental control of social outings and access to natural areas impacts children's ability to experience nature (Brussoni, Ishikawa, Brunelle, \& Herrington, 2017). Because nature contact is most notably socialized via modeling, children's sense of nature connectedness is dependent on parental modeling of nature connectedness. Modeling is the somewhat automatic ways in which children pick up on the 
general norms of a family and the overall accepted behaviors of a society. It shapes the child's understanding of themselves and others in the world around them, thus parents that model nature contact are socializing their children to nature connectedness (Laible et al., 2015).

Nature connectedness and developmental outcomes. More frequent positive experiences with nature increase the child's likelihood of developing nature connectedness (Beyer et al., 2015; Strife \& Downey, 2009). It can also positively influence child development overall because of how nature has been shown to support health and wellbeing, as well as closeness with those around them (Keniger et al., 2013). In turn, the outdoors can serve as a heightened context of social-emotional learning, such as in Ibrahim and Torquati's (2015) study that showed an uptick in children's respect for others and perspective-taking abilities (two aspects of social-emotional development that can lead to prosocial behavior) after exposure to nature-based learning activities. Thus, the outdoors could provide a unique opportunity for adults and children to engage in mutually-enjoyed activities that benefit their overall health and wellbeing through which parent-child relations can be built and maintained.

Prosocial behavior. Social and emotional development occurs throughout the lifespan as children are socialized to the world around them. One facet of social-emotional learning that is deeply rooted in childhood is the development of prosocial behavioral skills. Prosocial behavior is characterized by the intent to help others, such as through sharing, taking turns, helping someone out, or even following the rules (Eisenberg, Spinrad, \& Knafo-Noam, 2015). It is an ongoing aspect of development, through the display of prosocial behaviors, as well as a developmental outcome, prosociality.

Studying parents in connection with prosocial development is important because prosociality is modeled to children through direct and indirect observation of the behaviors of 
parents and other primary socialization influences in the child's life (Bornstein, 2015). Family interactions in nature and interactions between individuals and elements of nature have been shown to contribute to the development prosocial behavior (Ibrahim \& Torquati, 2015; McFarland, Zajicek, \& Waliczek, 2014). For example, participating in gardening can help a child understand how to care for something other than himself. Parents are one of the primary sources through which behavior is modeled to children; thus, the development of prosocial behavior can be fostered through witnessing parents' own prosociality. Examples of how this might look in the context of the family include but are certainly not limited to taking turns on a playground swing, witnessing a parent pick up litter in a park, and noticing the care that is shown for other living things when a parent is gardening (Ibrahim \& Torquati, 2015). One study even found that participants in an outdoor learning camp were more likely to display prosocial behavior at the end of the camp than at the beginning (Furman \& Sibthorp, 2014). Therefore, it seems plausible that nature connectedness is related to children's development of kind, sharing behavior.

\section{Summary}

This study's objective is to contribute to the limited available literature and empirical evidence on the topic of nature connectedness overall as well as the specific focus area of the role that parents' nature connectedness has on children's developmental outcomes. Moreover, parents that understand the importance of nature contact in their child's development might be more likely to increase their child's access to nature. And lastly, because increased exposure to nature has been shown to increase the learning of prosocial behaviors (Furman \& Sibthorp, 2014), children with high levels of nature connectedness may also display more prosocial behaviors. To analyze all of this, a survey correlational design was initiated to gather information regarding children and their parents' interactions with nature and with each other. The study also 
specifically examined nature connectedness and parent-child connectedness in association with the development of the child's prosocial behavioral skills.

\section{Hypotheses}

The current study was designed to address the following gaps in literature: (1) Is there a correlation between nature connectedness and the relationship that one has with his or her parent/child?; (2) Is time spent in nature during childhood predictive of later extent to which one exposes his or her own child to nature?; and (3) Is there an association between time spent outdoors and socio-emotional learning - specifically that of prosocial behavior?

As such, was hypothesized that parent's nature connectedness will be positively correlated with parent supportive/engaged behavior (parent-child connectedness), suggesting that higher levels of parental contact with nature might be related to higher levels of parent-child connectedness (Bettmann \& Tucker, 2011; Keniger et al., 2013). It was also hypothesized to see a positive correlation between parent's nature connectedness and child's nature connectedness, further establishing the notion that higher levels of parent contact with nature could be linked with higher levels of child contact with nature due to parents' socialization to enjoyed activities using modeling of behavior, both directly and indirectly. Lastly, it was hypothesized that there will be a positive relationship between the child's level of nature connectedness and his or her prosociality, with higher levels of child nature connectedness being linked with higher levels of prosocial behavior due to the association between contact with nature and social-emotional development (Furman \& Sibthorp, 2014).

\section{Method}

\section{Participants}

Participants $(N=467)$ were recruited using Amazon Mechanical Turk, an online task- 
related platform that pays survey participants upon survey completion. Participants had to meet the following criteria for selection; be over the age of 18, reside in the United States of America, and currently be a parent of a child aged 2-10 years old.

The mean parent age was $33.91(S D=6.76$, range $=20-61)$, and $54 \%$ of the parentrespondents were male. Seventy-seven percent were classified as White/Caucasian, 10.7\% as Black/African American, and 5.\% as Asian. Less than one percent (0.4\%) also reported ethnicities of Spanish, Hispanic, or Latino. Almost half (48.4\%) had at least a bachelor's degree, $12 \%$ had a master's degree, $11.6 \%$ had an associate degree, and $7.9 \%$ had only a high school diploma or GED. The majority (74.7\%) were married and the mean annual household income was $\$ 55,000$. The mean child age was $5.70(S D=2.58$, range $=2-10)$, and $57 \%$ were male. Respondents were primarily clustered around larger cities in the US and along western and eastern shorelines. Although several respondents resided in rural contexts, most were situated in more suburban or completely urbans zones.

\section{Procedure}

A national sample was collected using the online service Amazon Mechanical Turk. Participants who chose to complete the study answered a series of qualifier questions to determine eligibility based upon parenthood status (yes or no) and age of child. Limiters were preset within Mturk to only allow residents of the United States to take the survey. Once all qualifications were met, participants followed the provided link to the online survey. Then, they were presented with a consent form detailing the nature of the study. Upon clicking the yes selection option (and thus consenting to participating in the study), respondents were presented a series of questions about themselves and their child. The questionnaires gathered demographic information pertaining to family history of nature contact exposure levels; parental 
connectedness to nature and perceived benefit (or harm) of nature contact to children; offspring history of nature contact exposure levels; and parent perceived amount of time the child spends outdoors, including activities that take place during that time. Survey respondents were paid one dollar upon successful completion of the full survey, an amount that is actually higher (per hour) than most tasks on Mturk pay (considering an estimated 5-10 minute completion time).

\section{Measures}

Parent nature connectedness. Mayer and Frantz' (2004) fourteen-question Connectedness to Nature Scale (CNS) was used to assess parent nature connectedness (Appendix A). The CNS has been proven reliable in numerous studies, with high internal consistency and ability to predict behavioral and lifestyle patterns (Mayer \& Frantz, 2004). Levels of nature exposure (contact) information were also gathered that addressed the amount of and extent of direct nature exposure, extent (magnitude) of exposure, regularity (frequency) of exposure, duration (length) of exposure, type of exposure (direct or indirect) and activities that occur during exposure. Parents were asked to indicate how much they agree with each statement based on how they generally feel. Prompts ranged from "I often feel disconnected from nature" to "I recognize and appreciate the intelligence of other living organisms.” Scores were coded 1 through 5 , with 1 being strongly disagree and 5 being strongly agree. A total nature connectedness score was calculated using the reverse scores of questions 4,12 , and 14 and by then averaging scores for the full 14-item questionnaire $(\alpha=.90)$.

Child nature connectedness. Sobko, Jia, and Brown's (2018) Parents of Preschool Children-Connectedness to Nature Index (CNI-PPC) was used to assess the child's level of nature connectedness (Appendix B). Parents answered questions about their child such as "My child treats plants, animals and insects with care," "My child feels the difference between 
outdoor and indoor," and "My child chooses to read about plants and animals." This scale consisted of 16-items, each completed by selecting one of five options across of likert scale, ranging from 1 being strongly disagree and 5 being strongly agree $(\alpha=.94)$. A total nature connectedness score was obtained by averaging scores for the full 16-item questionnaire, with higher total scores indicating higher levels of child nature connectedness.

Parent-child connectedness. Lovejoy, Weis, O'Hare, and Rubin's (1999) Parent Behavior Inventory (PBI) was used to analyze the parent-child relationship (Appendix C). The questionnaire asked the parent to think about how he or she and the child generally get along. Questions gauged two overall aspects of the parent's behavior: how supportive/engaged or how hostile/coercive their behavior was towards their child. The likert scale response options ranged from 0-not at all true (I do not do this) to 5-very true (I often do this). The hostile/coercive scale consisted of items $1,3,5,7,9,13,15,17,19$, and 20 and indicates the level of negative affect or indifference the parent displays towards the child $(\alpha=.73)$. This category describes negative parenting and/or disengaged parenting. The supportive/engaged scale consisted of items $2,4,6,8,10,11,12,14,16$, and 18 and indicates the level of warmth, acceptance, and responsiveness of the parent towards the child $(\alpha=.90)$. This category describes positive parenting and/or involved parenting.

It is important to note that parent-child connectedness was assessed in two distinct domains for this study, with the average total score for the hostile parental behavior subscale being reported separately from the average total score of the supportive parental behavior subscale.

Child prosocial behavior. The Strengths and Difficulties Questionnaire (SDQ) developed by Goodman, Meltzer, and Bailey (1998) was used to assess the child's prosociality 
(Appendix D). The questionnaire asked parents to consider how true certain behaviors were of their child over the past six months, giving responses of somewhat true, not true, and certainly true. The statements had parents considering how true the following were of their child: "is considerate of other people's feelings, shares readily with others, helpful if someone is hurt, kind to younger children, and often volunteers to help others." Statements selections of "not true" received a score of 0 ; "somewhat true", a 1; and "certainly true", a 2. A prosocial behavior score was calculated using the prosocial scale of the SDQ, a 5-item subscale which consisted of questions $1,4,9,17$, and $20(\alpha=.74)$. Higher total scores of this subscale demonstrated higher levels of prosociality, and lower scores demonstrated lower levels of prosociality.

\section{Data Analyses Plan}

A series of descriptive statistics were conducted to compute means, standard deviations, and ranges for all variables of interest (see Table 1 for a table of descriptives). To test the hypotheses the following correlations were examined: (1) parent nature connectedness and parent-child connectedness (2) parent nature connectedness and child nature connectedness; and (3) child nature connectedness and his or her prosocial behavior (see Table 2 for a table of the correlations).

\section{Results}

\section{Hypothesis 1}

The first hypothesis was that parents' nature connectedness would be positively correlated with parent supportive/engaged behavior (parent-child connectedness). As noted in Table 2, there was a significant, positive relation between parent nature connectedness and supportive/engaged behavior towards the child, $r(467)=.46, p=.001$. This means that parent nature connectedness was associated with the closeness of the parent-child relationship. This is 
suggestive of higher levels of parental contact with nature potentially being related to higher levels of parent-child connectedness (Bettmann \& Tucker, 2011; Keniger et al., 2013). There was also a significant, positive relation between parents' nature connectedness and hostile/coercive behavior towards the child, $r(467)=.30, p=.001$.

\section{Hypothesis 2}

The second hypothesis of the study was that parents' nature connectedness would be positively correlated with child nature connectedness. As noted in Table 2, there was a significant, positive relation between parent nature connectedness and child nature connectedness, $r(467)=.59, p=.001$, further establishing the notion that higher levels of parent contact with nature could be linked with higher levels of child contact with nature due to the child's internalization of the parents' socialized enjoyment of outdoor activities (Bornstein, 2015; Strife \& Downey, 2009).

\section{Hypothesis 3}

Lastly, it was hypothesized that child nature connectedness would be positively correlated with his or her prosocial behavior; however, the results of this study did not confirm the hypothesis. This could mean that child nature connectedness may not be linked to higher levels of prosocial behavior (Furman \& Sibthorp, 2014), or it could mean that there was error due to measurement.

\section{Discussion}

The purpose of this study was to contribute to the limited available literature on the concept of nature connectedness and how it impacts parents and children by examining associations between nature connectedness, parent-child connectedness, and prosocial behavior as well as by viewing it all with a developmental niche lens (Super \& Harkness, 1986). The 
necessity of this work stemmed from prior literature linking nature connectedness to subjective wellbeing (Mayer \& McPherson, 2004); parents as primary socialization agents for children's development (Bornstein, 2015); and parent-child connectedness' influence on child socioemotional outcomes, including prosocial behavior (Clark \& Ladd, 2000). It was hypothesized that higher levels of parent nature connectedness would be associated with higher levels of parent-child connectedness, as well as higher levels of child nature connectedness. It was also hypothesized that higher levels of child nature connectedness would be associated with higher levels of child prosocial behavior. The present study featured an overall link to the developmental niche through children's social and physical setting, which are largely determined by environmental interactions and relationships, such as the parent-child relationship (Super \& Harkness, 1986). This determines the extent that a parent feels it is necessary to socialize their children to nature, such as by their direct control of the amount of time a baby is outside, or even in the vicinity of a window.

The first hypothesis was confirmed by the current study, as parent nature connectedness was positively associated with parent-child connectedness. That is, parent-child relationships were shown to be connected to the extent of the parent's closeness with nature. As aforementioned, it is important to note that the PBI assessed parent-child connectedness in two distinct domains: an average total score for the hostile parental behavior subscale and an average total score of the supportive parental behavior subscale (Lovejoy, Weis, O'Hare, \& Rubin, 1999). It was not surprising that parent nature connectedness was positively correlated with parent supportive behavior; however, it was interesting to find that parent nature connectedness was also positively correlated with parent hostile behavior. This may be due to measurement error with the PBI. Indeed, Lovejoy, Weis, O'Hare, and Rubin (1999) make use of a more liberal 
interpretation of hostility than other parenting measures - something that the authors even mention in their article. To this, liberal is taken to mean a broader, more encompassing view of behaviors, as many of the items used to measure hostility (with the exception of items 3 and 13) are not necessarily indicative of negative parenting, but more are more typical parent-child interactions and/or parenting beliefs. Nonetheless, they fell closer to the category of hostile than they did the category of supportive (Lovejoy et al., 1999).

The second hypothesis was also confirmed by the current study, as parent nature connectedness was positively associated with child nature connectedness. That is, children were more likely to develop a closer connection to the outdoors if their parent also demonstrated a close relationship with nature. This is consistent with the nature connectedness literature and the socialization literature. This has important implications for families, educators, and practitioners alike because even though this study only tested for correlations, these findings could be suggestive of a possible causal relationship between parents' nature connectedness and the development of child's nature connectedness. It is known that parents are a primary socialization agent in the lives of their children (Grusec \& Davidov, 2015; Laible, Thompson, \& Froimson, 2015), thus, it is natural to assume parents' choices of what to expose their children to (their caregiver beliefs) would be influenced by what brings the parent enjoyment, such as certain hobbies, sports teams, or elements of nature. This is further supported by the developmental niche theory, as Super and Harkness (1986) suggest that parenting behavior is determined by the culture in which one is situated and by the parents own caretaker psychology; thus, parents that view nature as an important part of their own lives would be more likely to incorporate nature into their children's lives. Thus, it is likely that more exposure to nature by parents is related to children's higher levels of nature connectedness. 
The third hypothesis was not confirmed. That is, child nature connectedness was not significantly associated with child prosocial behavior. It was hypothesized that child nature connectedness would be positively associated with child prosocial behavior, but that was not demonstrated by the findings. It is intriguing that this study did not achieve statistical significance for this hypothesis, but it is possible that nature connectedness is simply just not related to prosociality. Maybe nature connectedness is more applicable to social or emotional competence, or maybe even to academic outcomes or emotion regulation, such as what Ulrich et al. (1991) saw in nature connectedness' association with stress reduction, or other socialemotional outcomes such as self regulation (Degenhardt \& Buchecker, 2012), or solely empathy (Cheng \& Monroe, 2012). Or maybe nature connectedness supports social-emotional development in a more universal way, slightly fostering separate elements that combine to foster positive development. Regardless, it is still something that requires further analysis, possibly by using other informants and/or measures of prosocial behavior such as Ladd and Profilet's (1996) Child Behavior Scale, in which teachers would report on the child's behavior; or Ji, Flay and DuBois's (2013) child self-report measure, the Social-Emotional and Character Development Scale. It is also likely that this hypothesis was not confirmed as a result of measurement error with the prosocial scale of the Strengths and Difficulties Questionnaire; indeed, this subscale was only made up of five items, and maybe these limited options, such as "My child often offers to help others," or "My child is considerate of others feelings" are hard for the parent to observe in the limited time that they are with the child at home, and thus do not provide an accurate representation of prosociality. In addition, the measurement of child nature connectedness was also limited. Specifically, while the CNI-PPC is a good indicator of child nature connectedness levels, it may be better used as a self-report measure (such as how it had been more frequently 
used in prior studies) than as a parent-report on the child's internalized feelings toward nature.

\section{Strengths, Limitations, and Future Directions}

The results of the present study are important because they have several real-world implications for researchers and parents. This study showed that nature truly is an important aspect in families' lives, suggesting that parents who value nature might have better relationships with their children as a result. The results of this study also suggest the important role that parents play in socializing their children to the outdoors, as previously demonstrated by Mayer et al. (2009) and Keisanen, Rauniomaa, and Siitonen (2017), supporting the present study's finding that parents' nature connectedness was associated with child nature connectedness.

Furthermore, the study included a large, representative sample with diverse backgrounds and geographic locations throughout the United States of America. Another advantage that this study had over many prior studies is that it gathered information about parenting behaviors and attitudes towards nature, and then related them to the child behaviors and attitudes towards nature. While many studies have analyzed how nature influences the child in a school setting (Barros, Silver, \& Stein, 2009), there has been virtually no work examining the role of parenting behavior or the parent-child relationship in children's socialization of nature connectedness.

The correlational method of this study contributes to the understanding of connections between nature and human development, but it does not test how or why any of the associations occur. For the present study, this means that just because there was a demonstrated a link between parent nature connectedness and parent-child connectedness, we cannot conclude that parents' nature connectedness is the reason for the stronger relationship with the child, nor can we conclude that parents' hostile behaviors or supportive behaviors were responsible for the demonstrated stronger parents' nature connectedness. An analysis of the direct processes through 
which these relationships emerge is necessary in order to better understand causal relationships. Zelenski and Nisbet's (2014) study found similar results with nature connectedness, showing that overall connectedness with nature predicted happiness, but they also recommend additional studies to confirm the direction of causality. That is, studies that elicit inquiry into the proximal processes through which nature-connectedness develops will be worthwhile. One way that this could be done is by replicating Mayer, Frantz, Bruehlman-Senecal, and Dolliver's (2009) experimental design in which a modified version of the Connectedness to Nature Scale was used to analyze the mechanisms through which nature connectedness contributed to positive developmental outcomes. This study used the modified version of the Connected to Nature Scale on the basis of the respondents' current state of mind (as opposed to thinking of how he or she generally feels). Each of the items on the CNS(State) began with phrases such as, "I presently recognize...", "Right now...", or "At this moment...". A full example item would be "At the moment, I'm feeling that the natural world is a community to which I belong." It was used to test for differences in indoor and outdoor settings in order to gauge the individual's state of nature connectedness in varying locations, and to evaluate differences in effect of indirect versus direct forms of nature contact; whereas, the form of the CNS used in this study only tested for nature connectedness at one time point, and in terms of what the respondent generally feels.

Longitudinal studies using path analyses could also better determine causal inferences, direction of effects, and indirect or direct effects. Future studies might also consider using Schultz' (2002) one-item Inclusion of Nature in Self Scale (INS) to assess both child and parent individual nature connectedness levels, as it has been shown to be a consistently reliable and valid measure of nature connectedness in prior studies, and using the same standardized measure to assess both the parent and the child levels of nature connectedness might help account for any 
differences that might arise and increase the generalized understanding of the concept. In addition, acquiring detailed information about parents' prior childhood context would also be of relevance. This would provide a better understanding as to how the neighborhood context and the proximity to nature might contribute to overall connections with nature.

In closing, the current study contributes to the emerging literature on nature connectedness as well as furthers the knowledge about how parent socialization of children occurs in relation to nature contact. It revealed that multiple parent characteristics, including parent nature connectedness, parent hostile behavior, and parent supportive behavior, are associated with child nature connectedness, and that child nature connectedness and parent nature connectedness are associated with parent-child connectedness. Policies, procedures, and practices aimed at increasing child and parent nature contact will be especially important for those children and families who live in more urban contexts and have fewer direct opportunities to interact with nature. It could promote nature connectedness and better parent-child relationships, connection, and happiness levels, as nature connectedness has been shown to do, which could potentially offset the diminished opportunity for nature contact. 


\section{References}

Barros, R. M., Silver, E. J., \& Stein, R. E. K. (2009). School recess and group classroom behavior. Pediatrics, 123, 431-436.

Bento, G., \& Dias, G. (2017). The importance of outdoor play for young children's healthy development. Porto Biomedical Journal, 2(5), 157-160.

Bettmann, J. E., \& Tucker, A. R. (2011). Shifts in attachment relationships: A study of adolescents in wilderness treatment. Child \& Youth Care Forum, 40(6), 499-519.

Beyer, K., Bizub, J., Szabo, A., Heller, B., Kistner, A., Shawgo, E., \& Zetts, C. (2015). Development and validation of the attitudes toward outdoor play scales for children. Social Science and Medicine, 133, 253-260.

Bornstein, M. H. (2015). Children's parents. In R. M. Lerner (Ed.), Handbook of Child Psychology and Developmental Science: Ecological Settings and Processes (pp. 55-108).

Bowlby, J. (1969). Attachment and Loss, Vol. 1: Attachment. Attachment and Loss. New York: Basic Books.

Braithwaite, S. R., Steele, E., Spjut, K., Dowdle, K. K., \& Harper, J. (2015). Parent-child connectedness mediates the association between marital conflict and children's internalizing/externalizing outcomes. Journal of Child and Family Studies, 24(12), 36903699.

Bratman, G. N., Hamilton, J. P. \& Daily, G. C. (2012). The impacts of nature experience on human cognitive function and mental health. Annals of the New York Academy of Sciences, 1249, 118-136.

Brussoni, M., Ishikawa, T., Brunelle, S., \& Herrington, S. (2017). Landscapes for play: Effects of an intervention to promote nature-based risky play in early childhood centres. Journal 
of Environmental Psychology, 54, 139-150.

Cheng, J. C.-H., \& Monroe, M. C. (2012). Connection to nature: Children's affective attitude toward nature. Environment and Behavior, 44(1), 31-49.

Clark, K. E., \& Ladd, G. W. (2000). Connectedness and autonomy support in parent-child relationships: Links to children's socioemotional orientation and peer relationships. Developmental Psychology, 36(4), 485-498.

Degenhardt, B., \& Buchecker, M. (2012). Exploring everyday self-regulation in nearby nature: Determinants, patterns, and a framework of nearby outdoor recreation behavior. Leisure Sciences, 34(5), 450-469.

Eisenberg, N., Spinrad, T. L., \& Knafo-Noam, A. (2015). Prosocial Development. In R. M. Lerner (Ed.), Handbook of Child Psychology and Developmental Science.

Furman, N., \& Sibthorp, J. (2014). The development of prosocial behavior in adolescents: A mixed methods study from NOLS. Journal of Experiential Education, 37(2), 160-175.

Frumkin, H., Bratman, G. N., Breslow, S. J., Cochran, B., Kahn Jr., P. H., Lawler, J. J., Levin, P. S., Tandon, P. S., Varanasi, U., Wolf, K. L., \& Wood, S. A. (2017). Nature contact and human health: A research agenda. Environmental Health Perspectives, 125(7) 1-18.

Goodman, R., Meltzer, H., \& Bailey, V. (1998). The strengths and difficulties questionnaire: A pilot study on the validity of the self-report version. European Child \& Adolescent Psychiatry, 7(3), 125-130.

Grusec, J. E., \& Davidov, M. (2015). Analyzing socialization from a domain-specific perspective. In J. E. Grusec \& P. D. Hastings (2015). (Eds.), Handbook of socialization: Theory and research (158-181). New York, NY: Guilford Press.

Ibrahim H, A. \& Torquati, J. (2015). The power of nature: Developing prosocial behavior toward 
nature and peers through nature- based activities. Faculty Publications, Department of Child, Youth, and Family Studies, 116.

Ji, P., Flay, B. R., \& DuBois, D. L. (2013). Social-emotional and character development scale: Development and initial validation with urban elementary school students. Journal of Research in Character Education, 9, 121-147.

Keniger, L. E., Gaston, K. J., Irvine, K. N., \& Fuller, R. A. (2013). What are the benefits of interacting with nature? International Journal of Environmental Research and Public Health, 10(3), 913-935.

Keisanen, T., Rauniomaa, M., \& Siitonen, P. (2017). Transitions as sites of socialization in family interaction outdoors. Learning, Culture, and Social Interaction, 14, 24-37.

Laaksoharju, T., \& Rappe, E. (2017). Trees as affordances for connectedness to place: A framework to facilitate children's relationship with nature. Urban Forestry \& Urban Greening, 28, 150-159.

Ladd, G. W., \& Profilet, S. M. (1996). The child behavior scale: A teacher-report measure of young children's aggressive, withdrawn, and prosocial behaviors. Developmental Psychology, 32(6), 1008-1024.

Laible, D., Thompson, R. A., \& Froimson, J. (2015). Early socialization: The influence of close relationships. In J. E. Grusec \& P. D. Hastings (2015). (Eds.), Handbook of socialization: Theory and research (41-51). New York, NY: Guilford Press.

Lovejoy, C. M., Weis, R., O'Hare, E., \& Rubin, E. (1999). Development and initial validation of the parent behavior inventory. Psychological Assessment, 11. 534-545.

Lumber, R., Richardson, M., \& Sheffield, D. (2017) Beyond knowing nature: Contact, emotion, compassion, meaning, and beauty are pathways to nature connection. PLOS ONE, 12(5): 
e0177186.

Mayer, S. F., \& Frantz, C. M. (2004). The connectedness to nature scale: A measure of individuals' feeling in community with nature. Journal of Environmental Psychology, 24, 503-515.

Mayer, S. F., Frantz, C. M., Bruehlman-Senecal, E., \& Dolliver, K. (2009). Why is nature beneficial? The role of connectedness to nature. Environment and Behavior, 41, 607-643.

McFarland, A. L., Zajicek, J. M., \& Waliczek, T. M. (2014). The relationship between parental attitudes toward nature and the amount of time children spend in outdoor recreation. Journal of Leisure Research, 46(5), 525-539.

Schultz, P. (2002). Inclusion with nature: The psychology of human-nature relations. Psychology of Sustainable Development, 61-78.

Seymour, V. (2016). The human-nature relationship and its impact on health: A critical review. Frontiers in Public Health, 4(260), 1-11.

Sobko, T., Jia, Z., \& Brown, G. (2018). Measuring connectedness to nature in preschool children in an urban setting and its relation to psychological functioning. PLOS ONE 13(11): $\mathrm{e} 0207057$.

Strife, S., \& Downey, L. (2009). Childhood development and access to nature: A new direction for environmental inequality research. Organization and Environment, 22(1), 99-122.

Super, C. \& Harkness, S. (1986). The developmental niche: A conceptualization at the interface of child and culture. International Journal of Behavioral Development, 9, 545-569.

Ulrich, R., Simons, R., Losito, B., Fiorito, E., Miles, M., \& Zelson, M. (1991). Stress recovery during exposure to natural and urban environments. Journal of Environmental Psychology 11(3), 201-230. 
Wilson, E. O. (1984). Biophilia. Cambridge, Mass.: Harvard University Press.

Zelenski, J. M., \& Nisbet, E. K. (2014). Happiness and feeling connected: The distinct role of nature relatedness. Environment and Behavior, 46(1), 3-23. 
Table 1

Descriptive Statistics for All Variables of Interest

\begin{tabular}{lccccc}
\hline \multicolumn{1}{c}{ Variable } & $N$ & $M$ & $S D$ & Minimum & Maximum \\
\hline Parent Nature Connectedness & 467 & 4.17 & 0.78 & 1.86 & 5.83 \\
Child Nature Connectedness & 467 & 4.75 & 0.87 & 1.00 & 6.00 \\
Parent Hostile Behavior & 467 & 4.06 & 0.81 & 1.00 & 6.80 \\
Parent Supportive Behavior & 467 & 5.20 & 1.25 & 1.00 & 7.00 \\
Child Prosocial Behavior & 467 & 2.90 & 0.68 & 1.00 & 4.00 \\
\hline
\end{tabular}


Table 2

Summary of Correlations for all Variables of Interest

\begin{tabular}{lccccc}
\hline \multicolumn{1}{c}{ Variable } & 1 & 2 & 3 & 4 & 5 \\
\hline 1. Parent Nature Connectedness & - & $.59 * *$ & $.31 * *$ & $.42^{* *}$ & -.08 \\
2. Child Nature Connectedness & & - & $.35^{* *}$ & $.65^{* *}$ & -.03 \\
3. Parent Hostile Behavior & & & - & $.24 * *$ & $.26^{* *}$ \\
4. Parent Supportive Behavior & & & - & $-.16^{* *}$ \\
5. Child Prosocial Behavior & & & & - \\
\hline
\end{tabular}

Note. $* p<.05$, two-tailed; $* * p<.01$., two-tailed 


\section{Appendix A}

\section{Connectedness To Nature Scale (CNS)}

Using the scale below, please answer each of the following questions in the spaces provided. There are no right or wrong answers. Simply state as honestly and candidly as you can what you generally feel.

\begin{tabular}{|c|c|c|c|c|}
\hline $\mathbf{1}$ & $\mathbf{2}$ & $\mathbf{3}$ & $\mathbf{4}$ & $\mathbf{5}$ \\
\hline $\begin{array}{l}\text { Strongly } \\
\text { disagree }\end{array}$ & & Neutral & & $\begin{array}{c}\text { Strongly } \\
\text { agree }\end{array}$ \\
\hline
\end{tabular}

1. I often feel a sense of oneness with the natural world around me.

2. I think of the natural world as a community to which I belong.

3. I recognize and appreciate the intelligence of other living organisms.

4. I often feel disconnected from nature.

5. When I think of my life, I imagine myself to be part of a larger cyclical process of living.

6. I often feel a kinship with animals and plants.

7. I feel as though I belong to the Earth as equally as it belongs to me.

8. I have a deep understanding of how my actions affect the natural world.

9. I often feel part of the web of life.

10. I feel that all inhabitants of Earth, human, and nonhuman, share a common 'life force'.

11. Like a tree can be part of a forest, I feel embedded within the broader natural world.

12. When I think of my place on Earth, I consider myself to be a top member of a hierarchy that exists in nature.

13. I often feel like I am only a small part of the natural world around me, and that I am no more important than the grass on the ground or the birds in the trees.

14. My personal welfare is independent of the welfare of the natural world. 


\section{Appendix B}

\section{Connectedness to Nature Index-Parents of Preschool Children (CNI-PPC)}

Using the scale below, please answer each of the following questions about your child.

\begin{tabular}{|c|c|c|c|c|c|}
\hline $\mathbf{1}$ & $\mathbf{2}$ & $\mathbf{3}$ & $\mathbf{4}$ & $\mathbf{5}$ \\
\hline $\begin{array}{l}\text { Strongly } \\
\text { disagree }\end{array}$ & & Neutral & & $\begin{array}{c}\text { Strongly } \\
\text { agree }\end{array}$ \\
\hline
\end{tabular}

1. My child likes to hear different sounds in nature

2. My child likes to see wild flowers in nature

3. Being in the nature makes my child feel peaceful

4. My child likes to garden and plant

5. My child enjoys collecting rocks and shells

6. My child enjoys touching animals and plants

7. My child feels sad when wild animals are hurt

8. My child is distressed when he/she sees animals being hurt

9. My child is heartbroken when animals pass away

10. My child believes that picking up trash on the ground can help nature

11. My child treats plants, animals and insects with care

12. My child enjoys recycling paper and bottles

13. My child notices wildlife wherever he/she is

14. My child chooses to read about plants and animals

15. My child feels the difference between outdoor and indoor

16. My child hears birds and other sounds in nature 


\section{Appendix C}

\section{Parent Behavior Inventory (PBI)}

Read each statement carefully. Think about how you and your child generally get along. Tell us how well the statement describes the way you usually act with your child.

0 not at all true (I do not do this)

1 a little true

2 somewhat true

3 moderately true

4 quite a bit true

5 very true (I often do this)

Example: I quarrel with my child.

If you spend a great deal of time quarreling with your child, you would mark a 5 in the space.

If you never quarrel with your child, you would mark a 0 in the space.

If you quarrel sometimes, but not much, you would mark a 1 or 2 .

If you quarrel often, but not all of the time, you would mark a 3 or 4 .

1. _ I l lose my temper when my child doesn't do something I ask him/her to do.

2. _ I I have pleasant conversations with my child.

3. __ I grab or handle my child roughly.

4. _ I I try to teach my child new things.

5. _ I I demand that my child does something (or stop doing something) right away.

6. _ My child and I hug and/or kiss each other.

7. _ I I complain about my child's behavior or tell my child I don't like what s/he is doing.

8. _ I laugh with my child about things we find funny.

9. __ When my child misbehaves, I let him/her know what will happen if s/he doesn't behave.

10. _ My child and I spend time playing games, doing crafts, or doing other activities.

11. _ I listen to my child's feelings and try to understand them.

12. _ I I thank or praise my child.

13. _ I spank or use physical punishment with my child.

14. _ I I offer to help, or help my child with things s/he is doing.

15. _ I threaten my child.

16. _ I comfort my child when s/he seems scared, upset, or unsure.

17. _ I say mean things to my child that can make him/her feel bad.

18. _ I I hold or touch my child in an affectionate way.

19. W When I am disappointed in my child's behavior, I remind him/her about what I've done for him/her.

20. _ When my child asks for help or attention, I ignore him/her or make him/her wait until later. 


\section{Appendix D}

\section{Strengths and Difficulties Questionnaire (SDQ)}

For each item, please mark the box for Not True, Somewhat True or Certainly True. It would help us if you answered all items as best you can even if you are not absolutely certain. Please give your answers on the basis of the child's behavior over the last six months or this school year.

\begin{tabular}{|c|c|c|c|}
\hline & $\begin{array}{l}\text { Not } \\
\text { True }\end{array}$ & $\begin{array}{c}\text { Somewhat } \\
\text { True }\end{array}$ & $\begin{array}{c}\text { Certainly } \\
\text { True }\end{array}$ \\
\hline Considerate of other people's feelings & & $\square$ & \\
\hline Restless, overactive, cannot stay still for long & & $\square$ & \\
\hline Often complains of headaches, stomach-aches or sickness & & $\square$ & $\square$ \\
\hline Shares readily with other children, for example toys, treats, pencils & & $\square$ & $\square$ \\
\hline Often loses temper & & $\square$ & $\square$ \\
\hline Rather solitary, prefers to play alone & & $\square$ & $\square$ \\
\hline Generally well behaved, usually does what adults request & & $\square$ & $\square$ \\
\hline Many worries or often seems worried & & $\square$ & $\square$ \\
\hline Helpful if someone is hurt, upset or feeling ill & & $\square$ & $\square$ \\
\hline Constantly fidgeting or squirming & & $\square$ & $\square$ \\
\hline Has at least one good friend & & $\square$ & \\
\hline Often fights with other children or bullies them & & $\square$ & $\square$ \\
\hline Often unhappy, depressed or tearful & & $\square$ & $\square$ \\
\hline Generally liked by other children & & $\square$ & $\square$ \\
\hline Easily distracted, concentration wanders & & $\square$ & \\
\hline Nervous or clingy in new situations, easily loses confidence & $\square$ & $\square$ & $\square$ \\
\hline Kind to younger children & & $\square$ & $\square$ \\
\hline Often argumentative with adults & & $\square$ & \\
\hline Picked on or bullied by other children & & $\square$ & $\square$ \\
\hline Often offers to help others (parents, teachers, other children) & & $\square$ & $\square$ \\
\hline Can stop and think things out before acting & $\square$ & $\square$ & $\square$ \\
\hline Can be spiteful to others & & $\square$ & $\square$ \\
\hline Gets along better with adults than with other children & $\square$ & $\square$ & $\square$ \\
\hline Many fears, easily scared & $\square$ & $\square$ & $\square$ \\
\hline Good attention span, sees work through to the end & $\square$ & $\square$ & $\square$ \\
\hline
\end{tabular}

